\title{
Chickpea (Cicer Arietinum L.) Production Among Smallholder Farmers in Damot Gale and Humbo Woredas of Southern Ethiopia
}

\author{
Besufekad Belayneh $^{1 \mathrm{a}}$, Tewoderos Tefera ${ }^{1}$ and Thomas Lemma ${ }^{1}$ \\ ${ }^{1}$ Hawassa University, Collage of Agriculture, School of Environment, Gender and Development \\ Studies. P.O.Box 05. Hawassa, Ethiopia
}

\begin{abstract}
This research was aimed to study the chickpea (Cicer arietinum L.) production among smallholder farmers in Damot Gale and Humbo Woredas. A multi-stage sampling technique was used in order to determine the sample respondents. By using simple random sampling techniques four sample Kebeles were selected. Cross sectional data were collected from 182 farmer households who were chickpea producers in 2016 production season. Primary data were collected from sample households using structured questionnaire. Descriptive statistics and econometric model were employed to analyze the data. To identify the production function of chickpea crops Cobbe-Douglas production function was employed. The study suggest interventions such as intensification strategies which increase yields through proper management and use of inputs, rural infrastructure improvement increases the likelihood of production of chickpea.
\end{abstract}

Key words: chickpea; production function; household; south ethiopia

\section{Introduction}

Pulses are important components of crop production in Ethiopia and it contributes considerably for attaining food and nutritional security (Tewodros, 2013). Pulse crops occupy about $13 \%$ of croplands in Ethiopia and the second most important elements in the national diet (CSA, 2015). In Ethiopia, Chickpea is a less labor- intensive, widely grown, important food crop and source of cash (Shiferaw et al., 2007). The Southern Nation, Nationalities and Peoples Region (SNNPR) production of chickpea accounts 3\% the total chickpea production in the country (Rashid et al.,2010).Chickpea productions of Humbo and Damot Gale Woredas in 2016 production season were 1,984,000 kg and 282,600 kg respectively (Humbo WoANR, 2017; Damot Gale WoANR, 2017).

Pulse crops production among stallholder farmers is highly constrained by many problems such as crop producers are at very subsistence level of farming due to small land size allocation, poor usage of chemical fertilizer for production, limited access to credit, poor market linkage, poor extension service resulted in quality deterioration, price volatility, prevalence of pulse crops diseases and erratic rainfall. If the above-mentioned problems are fixed the pulse crop production on smallholder farmers would be seriously solved and pulse crop production could be improve. The major objective of the study is to assess the chickpea crops production among smallholder farmers in the study areas. Specifically the objective of the study is to assess and fit the production function of chickpea.

The study Woredas have sufficient potential and environmental settings for production of chickpea. Some studies investigated the major constraints of chickpea crop production in the study sites. Tewodros (2013) reported that land shortage, low soil fertility and disease on chickpea crop were the major constraint limiting chickpea production in Damot Gale Woreda. A study in the Rift Valley of Ethiopia including Humbo and Damot Gale Woredas found that limited access to credit, poor market linkage and price volatility were also problems of

\footnotetext{
a Corresponding author email; belayneh.besufekad@gmail.com
} 
chickpea crop producers (Frehiwot, 2010). However, in the aforementioned study the chickpea crop production is not well explored in both the study Woredas.

The available literature on pulses dwell on the performance of the existing cultivars and biofortification of chickpea cultivars (Legesse et al., 2017; Gemechu et al., 2011; Lemma et al., 2013); wilt/root rot diseases in major chickpea growing areas (Tebkew and Chris, 2016); analysis of chickpea value chain in Southern Ethiopia (Tewodros, 2013). The available information on the production of chickpea in both study sites is not sufficient. Moreover, the recent expansion of chickpea in SNNPR also deserves new studies. Hence, this study designed to address the research gap to provide valuable information for practitioners, researchers, policy makers and producers. The study analyzed the production function of chickpea in the Humbo and Damot Gale Woredas of SNNPR

\section{Methodology}

\subsection{Description of the Study Area}

The study was conducted in Southern Nation, Nationalities and Peoples Region (SNNPR), Humbo and Damot Gale Woredas of Wolayta Zone. Humbo is one of the Woredas in Wolayta zone. The administrative center of Humbo is Tebela. The Woreda is located in $6^{0} 43^{\prime} \mathrm{N}$ latitudes and $37^{0} 45^{\prime} \mathrm{E}$ longitudes and 1100 to 2300 m.a.s.l. The agro-climate zone of the area comprises Woina-dega (30\%) and kola (70\%) (HumboWoANR, 2017). Based on the 2007 census conducted by the CSA, this Woreda has a total population of 125,441, of whom 63,017 are men and 62,424 women; about 6,247 or $4.98 \%$ of its population are urban dwellers. Damot Gale is located in 7 ${ }^{0} 58^{\prime} \mathrm{N}$ latitudes and $37^{0} 52^{\prime} \mathrm{E}$ longitudes and altitude of 1501 to $2050 \mathrm{~m}$.a.s.l. The administrative center of Damot Gale is Boditi. The Woreda agro-climate zone of the area is characterized by Woina-dega (Damot Gale WoANR, 2017). Based on the 2007 Census conducted by the CSA, the Woreda has total population of 151,079 , of whom 74,227 are men and 76,852 women; and about 24,133 or $15.97 \%$ of its population are urban dwellers.

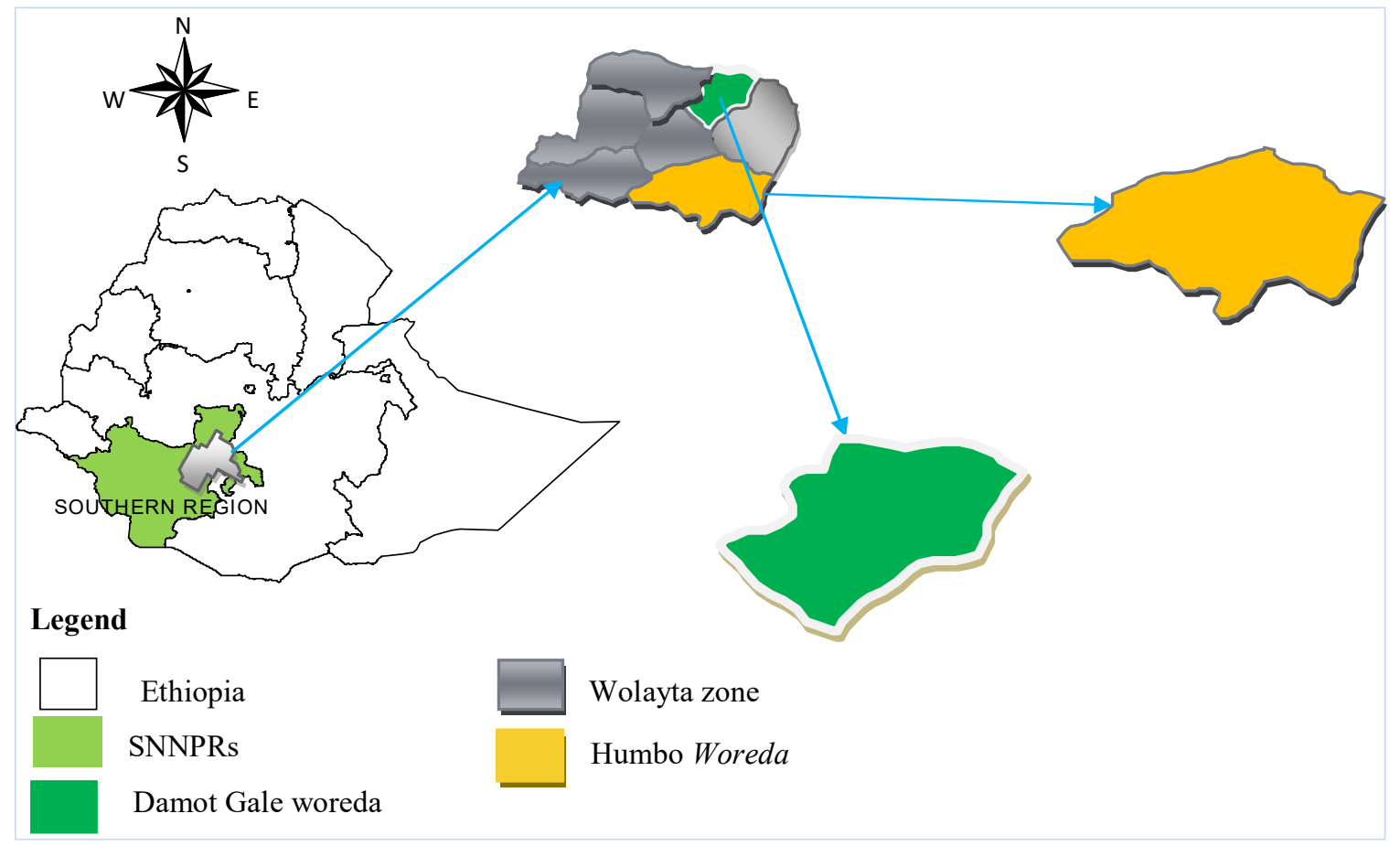

Figure 1: Geographical map of the study areas 


\subsection{Research Design}

\subsubsection{Data Types, Sources and Methods of data Collection}

The study used both primary and secondary sources of data, which is qualitative and quantitative in nature. The primary data were collected using questionnaire. Secondary data were obtained from various sources such as reports of Bureau of Agriculture and Natural Resources at different levels, CSA, NGOs, previous research findings, journal articles, e-books and other published and unpublished materials which are found to be relevant to the study.

To generate the necessary data from the primary sources, different procedural approaches such as face to face interview with sample respondent households were used. Most of research data were collected through questionnaires by means of household survey. The farm household survey data collected by using enumerators since most of farm households was not able to read and write. A total of 6 enumerators from Woreda office of agriculture and natural resources who speak the local language were selected and trained on the method of administering the interview schedule in general and on the content of the questionnaire in particular. The enumerators had a qualification of a minimum of college diploma. Before administrating the survey, questionnaire pretesting was conducted by enumerators to test the contents of the questionnaire, to measure how long it takes to fill a questionnaire and validate interviewing approaches. The pretesting was conducted in a Gacheno Kebele administrative. Then, the questionnaire was revised and content, which was unclear, was modified and removed. The field data collection were took 15 days, and all efforts were exerted to supervise on field level to check and correct gaps.

\subsubsection{Sampling Technique and Sample Size Determination}

\section{Sampling Technique}

In this study, multi-stage sampling technique was used. In the first stage, all Kebeles of the two Woredas (Damot Gale and Humbo Woredas) were stratified into chickpea producers and non-producers. From the 65 Kebeles about 40 Kebeles were found to be chickpea producers. Secondly, by using simple random sampling techniques, 4 sample Kebeles out of 40 pulse crops producer Kebeles were selected. Following the kebele selection, households were stratified in to producers and non-producers of chickpea crops. Finally, chickpea producing sample households were selected from chickpea producing stratum using systematic random sampling technique.

\section{Sample Size Determination}

An important decision to be taken while adopting a sampling technique is about the size of the sample. Hence, the sample size of the study was determined based on the scientific formula that designed to find out the appropriate size of the survey research. In the study, the Khotari (2004), sample size determination formula used in order to decide the size of sample population:

$$
n=\frac{Z^{2} * N * p * q}{e^{2}(N-1)+Z^{2} * p^{*} q}
$$

Therefore, by using the formula using $Z=1.96$ to $95 \%, p=0.5, q=1-p$ and $e^{2}=0.07, N=2,616$ values and the sample size calculated $\mathrm{n}=182$ (165 male and 17 female) which is the necessary sample size of the study.

Where: $-\mathbf{N}=$ total households, $\mathrm{n}=$ size of the sample, $\mathrm{Z}=$ standard variation at a given confidence level, $\mathrm{P}=$ proportion of successes, $\mathrm{q}=$ proportion of failures, $\mathrm{e}^{2=}$ acceptable error. 
Table1: Sample Size and Sample Distribution by Kebeles

\begin{tabular}{lcc}
\hline Sample Kebeles & $\begin{array}{c}\text { Chickpea Crops Producing } \\
\text { households }\end{array}$ & Selected Size of ample \\
\hline Gututo Larena & 550 & 39 \\
Abala Sipa & 823 & 59 \\
Taba & 776 & 48 \\
Gacheno & 467 & 36 \\
\hline Total & 2,616 & 182 \\
\hline
\end{tabular}

Source: Own computation based on data from WoANR (2017).

\subsection{Methods of Data Analysis}

\subsubsection{Cobb Douglas type production function}

The chickpea crops production in Damot Gale and Humbo Woredas was used the farm level cross section data which were collected through structured questionnaire in the year 2016/2017. The data to analyze chickpea production function was built-in Cobb-Douglas production. So, as Gujarati (2004) defined the Cobb-Douglas production function, in its stochastic form may be expressed as:

$$
y_{i}=\alpha x_{1}^{\beta 1} x_{2}^{\beta 2} x_{3}^{\beta 3} \ldots \ldots x_{n}^{\beta n} e^{u_{i}}
$$

Where: $\mathrm{y}_{\mathrm{i}}=$ output of chickpea measured in kilogram

$\beta_{1-} \beta_{n}=$ unknown parameters to be estimated,

$x_{1}-x_{n}=$ vector of explanatory variables,

$\mathrm{u}_{\mathrm{i}}=$ error term and $\mathrm{e}_{\mathrm{i}}=$ base of natural logarithm

The above equation is converted into the logarithmic form in order to facilitate the use of linear regression. Taking logarithm on both sides of the equation:

$$
\ln y_{i}=\alpha+\beta_{1} \ln x_{1}+\beta_{2} \ln x_{2}+\beta_{3} \ln x_{3} \ldots . . \beta_{n} \ln x_{n}+u_{i}
$$

\section{Results and Discussion}

\subsection{Socio-Economic and Demographic Characteristics of Respondents}

The average age and family size of the sample households were 40.1 years and 6 persons, respectively. The household respondents' average experience in farming was 11.4 years. On average chickpea producer households own about 0.29 hectares of land for chickpea production and owned 4.24 livestock measured in TLU. The sample households located 5.9 kilometer away from the nearest market place (Table 2). The households on average obtained an annual gross off-farm income of 1080.5 Birr. The lagged price of chickpea per quintal was 2063.20 (Table 2). The majority of the respondent households were applied improved variety (93\%), access to credit (79\%), and member of cooperative (77\%). Overwhelming majority (91\%) of respondents attained formal education (Table 2). 
Table 2: Socio-economic and demographic characteristics of chickpea marketed surplus

\begin{tabular}{llll}
\hline Variables & Variable Description & Mean & Std.dev. \\
\hline Age & Number of Years & 40.1 & 7.7 \\
Household size & Number of individuals of family & 6 & 1.7 \\
Farm experience & Number of years & 11.4 & 9.6 \\
Cultivated area & Measured in Hectares & 0.29 & 0.07 \\
Distance nearest market & Measured in Kilometer & 5.8 & 3.0 \\
Lagged Market price & Measured in Birr & 2063.2 & 584.6 \\
Off-farm activity income & Measured in Birr & 1080.5 & 2045.04 \\
Livestock holding & Measured in Tropical livestock unit & 4.2 & 2.4 \\
& & $\%$ & \\
Sex (male, \%) & $1=$ male, $0=$ female & 84.07 & \\
Improved Seed variety (\%) & $1=$ yes, 0= No & 92.86 & 78.57 \\
Access to credit (\%) & $1=$ yes, $0=$ No & 76.92 & \\
Cooperative membership (\%) & $1=$ yes, $0=$ No & 91.21 & \\
Education status (\%) & $1=$ formal education, $0=$ No & & \\
\hline
\end{tabular}

Note: $* * *, * *$ and $*$ represents significance at $1 \%, 5 \%$ and $10 \%$ probability levels, respectively.

Source: Own computation of survey data, 2016/17

\subsection{Chickpea Production Function}

The Cobb-Douglas production function adequately modeled the input-output relation of chickpea production in the study areas using Ordinary Least Squares (OLS) method. The usual inputs used as descriptive variables in production function were seed, fertilizer, land allocated and labor measured in man days for the chickpea production. The results shows that the coefficients of seed, fertilizer and land allocated was found to be positive and significantly affect chickpea output of the respondents as revealed by the computed t-test values. This implies that, any increase in the use of these production inputs would bring about increase in chickpea crops output. The $\mathrm{R}^{2}$ value for chickpea models was 0.69 . This implies that $69 \%$ of the variation in chickpea output was explained by the five independent variables include in the model respectively.

The following elasticities were generated from the Cobb-Douglas production function estimation of chickpea; seed varieties (0.41), Fertilizer use (0.047), land allocation (0.061), labor use (0.077) and Insecticides (0.003) (Table 3). Hence, the resulting returns to scale parameter obtained by summing these input elasticities is 0.6. This indicates that chickpea production in the study areas exhibits decreasing returns to scale. The sum of regression coefficients exceeds, less than and equal to one said to be increasing return to scale, decreasing return to scale and constant return to scale respectively. The higher elasticity of input variables would have greater impact in determining the level of output while lower elasticity of input variables would have lower impact in influencing level of chickpea crops production. Chickpea seed varieties had the largest elasticity, followed by land allocation. This suggests that any interventions to increase production of seed varieties and fertilizer for chickpea would create significant achievements of production in the study sites.

The results on table 3 showed that varieties of chickpea seed variables were highly significant at $1 \%$ level. The amount calculated approximately of 0.41 shows that a $1 \%$ raise in the amount incurred for improved seed directs to a $41 \%$ increase in the amount produced of chickpea. On the other hand the result also mean that if household farmers spend on improved chickpea seed varieties which in high amount than the existing broadly used local seed varieties and there is a potential for productivity boost.

The fertilizer variable was highly significant at $1 \%$ level, meaning that a $1 \%$ increase in fertilizer increases chickpea production by $4.7 \%$ (Table 3 ). This suggests that increasing the amount of fertilizer used would contribute to higher chickpea production in the area. There is diminishing return to invest on fertilizer. This result indicates that the current usage of fertilizer in the study area is less than the required and the reasons were high price cost to buy fertilizer and lack of funds. 
Table 3: Results of the Cobb-Douglas production function of Chickpea in the study areas

\begin{tabular}{lll}
\hline LnChickpea production $(\mathrm{Kg})$ & Coefficient & t-value \\
\hline $\ln$ Fertilizer $(\mathrm{kg} / \mathrm{ha})$ & 0.0466817 & $2.89^{* * *}$ \\
$\ln$ Seed $(\mathrm{kg} / \mathrm{ha})$ & 0.4109025 & $5.19^{* * *}$ \\
$\ln$ Chickpea land(ha) & 0.0612012 & 0.57 \\
$\ln$ Labor use (MD) & 0.0765113 & 0.82 \\
$\ln I n s e c t i c i d e ~(k g)$ & 0.0027001 & 0.17 \\
Constant & -0.661110 & $-1.75^{*}$ \\
\hline
\end{tabular}

Number of obs $=182, \mathrm{R}^{2}=0.6946$, Prob. $>\mathrm{F}=0.0000$

Note: Likelihood-ratio test of sigma_u $=0 ; \operatorname{chibar}^{2}(01)=0.00$ prob $>=\operatorname{chibar}^{2}=1.000$.

$* * *, * *$ implies significant at $1 \%$ and $5 \%$.

Source: Computed from Field Survey Data (2017).

\section{Conclusion}

The Cobb-Douglas production function adequately modeled the input-output relationship for chickpea production in the study areas. The findings were consistent with the economic theory; the coefficients of chickpea seed was significant showing that it was the most important factors affecting chickpea production in Damot Gale and Humbo Woredas. Moreover, the fertilizer use of chickpea production in kilogram was also significant in the study areas.

\section{Acknowledgments}

I would also like to express my sincere gratitude to the International Development Research Centre (IDRC), Ottawa, Canada and Global Affairs Canada through Canadian International Food Security Research Fund (CIFSRF) projects for conducting me the grant for scholarship and covering full tuition fee to my MSc. thesis.

\section{Reference}

Central Statistical Agency. 2015/16.Crop and Livestock Products Utilization Agricultural Sample Survey (Private Peasant Holdings, "Meher" Season), Vol. VII Statistical Bulletin 586, Addis Ababa: JULY, 2016. pp.195.

Central Statistics Agency. 2007. Central statistics agency population of 2007. Addis Ababa: CSA.

Frehiwot Mulugeta.2010.Profile of Haricot bean production, supply, demand and marketing issues in Ethiopia, Ethiopia Commodity Exchange Authority.Addis Ababa.pp.5-8

Gemechu K., Endashaw B., Emana G., Muhammad I., Kifle D. and Fassil A. 2011. Characterization of Ethiopian Chickpea ( Ethiopian Chickpea (Cicer arietinum L.) Germplasm Accessions for Response to Infestation by Adzuki Bean Beetle (Callosobruchus chinensis L.). Ethiop. J. Agric. Sci. 21:41-65.

Gujarati, N.D. 2004. Basic Econometrics, fourth edition, Mc Graw Hill, New York.

Khotari,C.R. 2004. Research methodology. Methods and Techniques: second edition. Former principal college of commerce, University of Rajathan, Jaipur India.

Legesse H., Bunyamin T., Walelign W., and Hussein M. 2017. Towards Zinc Biofortification in Chickpea: Performance of Chickpea Cultivars in Response to Soil Zinc Application. www.mdpi.com/20734395/7/1/11/htm. pp.1-14.

Lemma, W., Wassie, H. And Sheleme, B. (2013).Response of Chickpea (CicerArietinum L.) to Nitrogen and Phosphorus Fertilizer S in Halaba and Taba, Southern Ethiopia.Ethiopian Journal of Natural Resources 13(2):115-128.

Rashid, S., Yirga, C., Behute, B. and Lemma, S. (2010). Pulses Value Chain in Ethiopia: Constraints and opportunities for enhancing export. International Food Policy Research Institute. Washington, DC, USA. $1: 10$ 
Shiferaw,B., and Hailemariam, T. 2007. Structure and functioning of chickpea markets in Ethiopia: Evidence based on analyses of value chains linking smallholders and markets. IPMS Working Paper 6, ILRI, Nairobi, Kenya. 55 pp.

Tebkew Damte\& Chris O.Ojiewo.(2016).Current status of wilt/root rot diseases in major chickpea growing areas of Ethiopia. Archives of Phytopathology and Plant Protection, 49:9-10.

Tewodros Tefera. 2013. Market and consumer studies of pulse crops in Southern Ethiopia. ,Hawassa University School of Environment, Gender and Development Studies.Hawassa, Ethiopia. pp.4-5. 